\title{
MONITORES EM AÇÃO NO ENSINO COLETIVO DE CORDAS DA
} UFC

\author{
Hayrles da Conceição Freitas de Moraes Alcântara1; Liu Man Ying² \& Dora Utermohl de Queiroz ${ }^{3}$
}

${ }^{1}$ Bolsista e graduando pela Universidade Federal do Ceará (UFC). E-mail: hayrles_freitas@ @otmail.com; ${ }^{2}$ Professora de violino e viola na Universidade Federal do Ceará (UFC). E-mail: liu_ufc@yahoo.com.br; ${ }^{3}$ Professora de violoncelo e contrabaixo na Universidade Federal do Ceará. E-mail: doraqueirozdello@gmail.com

Artigo submetido em Setembro/2017 e aceito em Outubro/2017

\section{RESUMO}

Esta pesquisa faz parte de um conjunto de ações investigatórias sobre o ensino coletivo de instrumentos de cordas friccionadas na Universidade Federal do Ceará - UFC. O objetivo desse trabalho é compreender a importância dos monitores no desenvolvimento da metodologia do ensino coletivo de cordas no curso de música da UFC, no projeto Sinfonia.br e qual a relevância dessa experiência para a formação dos monitores na visão deles mesmos. A abordagem deste trabalho será qualitativa em um estudo de caso e sua metodologia se dará por meio de análise documental e uma entrevista grupo focal com todos os monitores que atuam com a metodologia na UFC. Sobressaiu-se nesta pesquisa a evolução dos projetos, o aumento do número de alunos inscritos e nas experiências proporcionadas aos monitores dessas ações de extensões que amadurecem sua formação docente, artístico, técnico-instrumental e humana a partir dessa oportunidade.

PALAVRAS-CHAVE: Ensino coletivo de cordas. Monitoria. Ações de extensão.

\section{MONITORS IN ACTION IN THE UFC TEACHING COLLECTIVE OF STRING}

\begin{abstract}
This research is part of a set of investigative actions on the collective teaching of stringed instruments at the Federal University of Ceará - UFC. The objective of this work is to understand the importance of the monitors in the development of the methodology of collective teaching of strings in the music course of the UFC, in the project Sinfonia.br and what is the relevance of this experience for the formation of the monitors in their own vision. The approach of this work will be qualitative in a case study and its
\end{abstract}

methodology will be given through documentary analysis and a focus group interview with all the monitors that act with the methodology in the UFC. In this research the evolution of the projects, the increase in the number of enrolled students and in the experiences provided to the monitors of these extensions actions, maturing their teaching, artistic, technical-instrumental and human formation from this opportunity were highlighted in this research.

KEYWORDS: Collective teaching of ropes. Monitoring. Extension actions.

\section{INTRODUÇÃO}


Este trabalho de pesquisa faz parte de um conjunto de ações investigatórias sobre o ensino coletivo de cordas na Universidade Federal do Ceará - UFC. No processo de análise documental para a construção de um esquema histórico sobre o tema na instituição, encontrou-se um artigo do tipo relato de experiência escrito por uma aluna de violino de umas das ações de extensão do curso de música da UFC no qual a mesma pontua a importância da presença dos monitores para o seu desenvolvimento e inclusão na metodologia do ensino coletivo.

\begin{abstract}
A metodologia utilizada é o ensino coletivo que, regido pela professora efetiva da universidade, conta com a ajuda de bolsistas que contribuem com a formação da turma auxiliando a professora-regente [...] É importante ressaltar a relevância dessa metodologia para o professor assistente (aqui no caso estudantes da graduação) que ao mesmo tempo em que aprendem conteúdos também aprendem o processo didático (LIMA, 2016, p. 267).
\end{abstract}

Diante dessa indicação os pesquisados que tem trabalhado na empreitada referente à observação, compreensão, pesquisa e registro quanto ao ensino coletivo de cordas na Universidade Federal do Ceará decidiram investigar mais a fundo essa questão e reuniram-se a fim de escolher uma metodologia de pesquisa que melhor atendesse ao objetivo estabelecido: compreender a importância da presença dos monitores no desenvolvimento do ensino coletivo de cordas na UFC e a relevância dessas experiências na vida deles. Assim, escolheram a entrevista grupo focal como a mais propicia para tal finalidade.

O tópico a seguir abordará brevemente o ensino coletivo de cordas na UFC e explicará o processo de seleção dos monitores em questão assim como suas funções e posteriormente a esses tópicos detalhar-se-á a fundamentação de uma entrevista grupo focal para assim apresentar os resultados e as considerações finais.

\title{
2 O ENSINO COLETIVO DE CORDAS NA UFC
}

O ensino coletivo de cordas começou a compor a matriz curricular do curso de licenciatura em música da Universidade Federal do Ceará em 2016, porém, desde 2015 com a contratação das professoras Liu Man Ying e Dora Utermohl de Queiroz - ambas para atuarem como professoras de ensino coletivo de instrumentos de cordas friccionadas respectivamente violino/viola e violoncelo/contrabaixo - esta nova possibilidade já fazia parte da realidade dos 
estudantes da universidade e da comunidade com a criação de grupos de extensão.

Sobre as vantagens do ensino coletivo de cordas Ying $(2007$, p. 8) afirma:

"O ensino coletivo de cordas, como metodologia, mostrou-se bastante eficaz ao longo dos anos de seu emprego, como forma de atingir um público maior no início de seu aprendizado musical, além de propiciar integração social, despertar maior interesse nos alunos iniciantes e incentivo para a continuação dos estudos através da dinâmica estimulante de classe de aula." (YING, 2007, p. 8)

O processo de inclusão da metodologia de ensino coletivo de instrumentos de cordas está intimamente ligado à criação da orquestra sinfônica da Universidade Federal do Ceará como se pontua abaixo:

\begin{abstract}
“A Orquestra de Câmara da UFC surgiu a partir da inserção de novos instrumentos no currículo do Curso de Música da Universidade Federal do Ceará e da demanda de alunos que passaram a nele estudar. Em 2011, alunos se reuniam em duos e trios de violino, dando origem ao Grupo Encordoado, que, em 2012, agregou flautas transversais. Em 2013 grupo passou a contar com violoncelo, flauta doce e fagote, e no primeiro semestre de 2014 o grupo, ainda com o nome de Encordoados, passou a ser regido pelo professor e fagotista Prof. Jáderson Teixeira. Em meados de 2014 foi contratado o professor de metais e trompetista Leandro Libardi Serafim, que passou a dividir a coordenação do grupo com o Prof. Jáderson Teixeira. A expansão da quantidade de instrumentos ocorrida fez com que o grupo passasse a ser chamado de Orquestra de Câmara da UFC. Em 2015 ocorreu a contratação da professora de violoncelo Dora Utermohl de Queiroz e o grupo ampliou-se ainda mais (...) Desde seu início a Orquestra de Câmara da UFC teve como foco a execução de repertório essencialmente brasileiro". (<http://www.ufc.br/noticias/noticias-de-2015/6842orquestra-de-camara-da-ufc-realiza-hoje-23-concerto-pelos-50-anos-do-teatrouniversitario> Acesso em 10/05/2017).
\end{abstract}

A partir de 2016 fixou o novo projeto político pedagógico do curso de música da UFC com a inclusão das disciplinas optativas instrumentais em ensino coletivo de cordas friccionadas violino/viola, violoncelo/contrabaixo, sopro-madeira e sopro-metais. Sobre esse momento de inovações no curso de música Melo (2016, p. 248) afirma: “A partir da oferta das disciplinas instrumentais de violoncelo e violino ofertadas pela graduação, proporcionou a ampliação de possibilidade de formação para os estudantes de cordas da graduação, comunidade e integrantes da orquestra".

Atualmente além da oferta das disciplinas das práticas instrumentais citadas acima, existem também grupos de extensão que atendem de forma gratuita alunos dos demais cursos e pessoas da comunidade em geral que querem aprender a tocar algum desses instrumentos.

Listar-se-á abaixo os grupos de extensão da prática coletiva de instrumentos de cordas friccionadas atuantes na Universidade Federal do Ceará: 
Tabela 1: Grupos de Extensão de prática coletiva de instrumentos de cordas friccionadas da UFC

\begin{tabular}{|c|c|c|c|}
\hline Nome do grupo & $\begin{array}{c}\text { O grupo } \\
\text { existe desde: }\end{array}$ & $\begin{array}{l}\text { Quantidade de } \\
\text { integrantes: }\end{array}$ & $\begin{array}{c}\text { Instrumentos } \\
\text { trabalhados } \\
\text { no grupo: }\end{array}$ \\
\hline $\begin{array}{l}\text { Grupo de violoncelos } \\
\text { da UFC }\end{array}$ & Março/2015 & 12 & Violoncelo \\
\hline $\begin{array}{c}\text { Grupo de violinos e } \\
\text { viola }\end{array}$ & Agosto/2015 & 12 & Violino e viola \\
\hline Ipê Amarelo & Março/2016 & 7 & Violino e viola \\
\hline $\begin{array}{c}\text { Camerata de cordas da } \\
\text { UFC }\end{array}$ & Março/2016 & 25 & $\begin{array}{l}\text { Violino, viola, } \\
\text { violoncelo e } \\
\text { contrabaixo }\end{array}$ \\
\hline Graúna & Agosto/2016 & 15 & Violino e viola \\
\hline Sabiá & Março/2017 & 35 & Violino e viola \\
\hline $\begin{array}{c}\text { Orquestra de cordas } \\
\text { da UFC }\end{array}$ & Março/2017 & 26 & $\begin{array}{l}\text { Violino, viola, } \\
\text { violoncelo e } \\
\text { contrabaixo }\end{array}$ \\
\hline Bem-te-vi & Março/2017 & 24 & $\begin{array}{c}\text { Violino (crianças de } \\
8-10 \text { anos) }\end{array}$ \\
\hline Tico tico & Março/2017 & 14 & $\begin{array}{l}\text { Violino e violoncelo } \\
\text { (crianças de } 11-13 \\
\text { anos) }\end{array}$ \\
\hline
\end{tabular}

Fonte: Elaboração dos autores.

Os grupos de extensão de ensino coletivo de cordas atendem crianças, jovens e adultos que muitas vezes chegam conhecimento nenhum de teoria musical e sem ter o instrumento (apesar de a universidade dispor de alguns instrumentos para serem usados em seus espaços, é de responsabilidade do aluno adquirir o seu para manter uma rotina de estudos em casa), assim, para atender a essa demanda tem-se a colaboração de monitores que podem ser bolsistas remunerados ou bolsistas voluntários que desenvolvem diversas funções que se pontuará no subtítulo abaixo.

\section{REFERENCIAL TEÓRICO}

O referencial teórico baseia-se em: Ying $(2007 ; 2012)$ quanto aos métodos de ensino coletivo de cordas friccionadas. A autora em seus trabalhos de mestrado e doutorado para o desenvolvimento de método para o ensino coletivo de violino Ying desenvolve exercícios 
preparatórios e parâmetros para o ensino de instrumentos de cordas friccionadas. Sobre metodologia de trabalhos científicos tem-se Gil (2009) e Duarte e Barros (2006) que fundamentaram os processos para a entrevista grupo focal, principal método escolhido para aferição das informações desse trabalho e Melo (2016) sobre a importância dos ambientes coletivos de formação em seu relato de experiência sobre o ensino coletivo de cordas na Universidade Federal do Ceará.

\section{MATERIAIS E MÉTODOS}

Dos monitores atuantes no ensino coletivo de cordas na Universidade Federal do Ceará há os que são bolsistas remunerados e os que são voluntários. Sobre a primeira modalidade citada esclarecesse que esta somente é possível por existirem vários setores da universidade que lançam editais durante todo o ano para a inscrição de projetos pleiteando bolsas remuneradas e dentre esses setores podemos citar a Pró-Reitoria de Extensão - PREX, a Pró-Reitoria de Pesquisa e Pós-graduação PRPPG, a Secretaria de Cultura Artística - Secult Arte e a Pró-Reitoria de Graduação - Prograd como os principais incentivadores das práticas de extensão de ensino coletivo de cordas na UFC.

A modalidade de bolsista voluntário não envolve uma remuneração mensal como uma bolsa, no entanto, além da experiência docente conquistada, ao final do ano letivo o aluno voluntário pode solicitar uma declaração sobre a sua colaboração e contabilizar essas horas as suas atividades complementares.

O processo de seleção dos monitores (remunerados ou não) acontece no início de cada ano letivo e para concorrer à vaga não necessariamente o aluno precisa ser do curso de música, pode ser também algum aluno de outro curso que tenha experiência com o instrumento de outro ambiente. Nesse sentido o pré-requisito básico para se concorrer a uma vaga remunerada é ter vínculo com a instituição.

O referido processo seletivo para monitoria envolve no mínimo três momentos: inscrição, análise curricular (histórico acadêmico e currículo lattes) e entrevista/audição, assim, os alunos aprovados são direcionados de acordo com suas potencialidades para atuarem em diferentes funções nas disciplinas ofertadas aos alunos do próprio curso de 
música, nos grupos de extensão e grupos de prática orquestral.

A homogeneidade das turmas de extensão delibera diferentes demandas aos monitores, assim, sempre orientados pelas professoras Liu Man Ying e Dora Utermohl de Queiroz os monitores desempenham funções como: suporte as aulas de prática instrumental, planejamento e acompanhamento de reforço individual ou em grupo (atividade destinada aos estudantes com mais dificuldade), afinação dos instrumentos, aulas de leitura musical, percepção e solfejo aos alunos que chegam aos grupos extensão sem nenhum conhecimento de teoria musical, aulas de musicalização aos alunos na faixa etária de 7 a 12 anos, organização dos espaços de estudo, dos equipamentos (ex.: estantes), das pastas, partituras e organização e participação em eventos organizados pela instituição referente ao ensino coletivo de instrumentos.

A seguir, apresentar-se-á as fundamentações quanto à entrevista do grupo focal, o motivo da escolha da mesma para esta pesquisa assim como o produto de sua aplicação com os monitores do ensino coletivo de cordas da UFC.

\section{ENTREVISTA GRUPO FOCAL}

A entrevista focus group ou entrevista grupo focal para Duarte e Barros (2006) é: "uma entrevista coletiva que busca identificar tendências. A maior busca é a de compreender e não inferir nem generalizar" (DUARTE; BARROS, 2006, p. 181).

Para uma maior concepção da fundamentação e da técnica envolvida em uma entrevista focus group faz-se necessário acrescentar as percepções de Gil (2009):

\footnotetext{
O focus group é um tipo de entrevista em profundidade realizada em grupo, que privilegia a observação e o registro de experiência e reações dos participantes. Essa entrevista é conduzida por um moderador, que introduz um tópico a um grupo de respondentes e direciona sua discussão sobre o tema de uma maneira não estruturada. Constitui, portanto, técnica apropriada para obtenção de dados em pesquisa que tenham por objetivo saber como as pessoas consideram uma experiência, um evento ou um fato (GIL, 2009, p. 83-84).
}

A escolha por essa metodologia de pesquisa deu-se não apenas pela junção das concepções coletivas estudadas, também pela flexibilidade na condução desse tipo de entrevista e a sinergia gerada pela participação conjunta do grupo de entrevistados (DUARTE; BARROS, 2006, p. 182) que são suas principais características, ou seja, funciona 
como um grande bate papo com um tema e questões definidos que não são direcionadas especificamente a nenhum integrante, mas, aqueles que se sentirem a vontade para colaborar e compartilhar suas percepções naquele momento.

\title{
6 MONITORES EM AÇÃO
}

No dia 10 de junho de 2017 foi realizada uma entrevista grupo focal com os monitores que atuam junto ao ensino coletivo de cordas na Universidade Federal do Ceará. A entrevista foi realizada no prédio do Instituto de Cultura e Arte - ICA da instituição, na sala de ensaios da orquestra. No total são 15 os monitores da área estudada, porém, do dia da realização da entrevista estavam presentes treze, os que faltaram justificaram suas ausências.

Com a finalidade de entender qual a concepção que os próprios monitores têm com relação a trabalho que desenvolvem, o primeiro questionamento realizado foi - na visão deles - qual a função de um monitor de uma aula de ensino coletivo de cordas na Universidade Federal do Ceará? Dentre as respondas emitidas recortou-se as citações a baixo por melhor refletirem a ideia geral manifestada por todos.

\begin{abstract}
Acredito que a nossa função tem sido pedagógica, nossa função tem sido formativa, tem sido uma participação relevante e formadora aqui no âmbito da Universidade Federal do Ceará. Estamos com dois anos desse processo, basicamente, e nós bolsistas, nós monitores, extensionistas, estamos colhendo esses frutos de aprendizagem, planejamento, conhecimento pedagógico, graças também ao trabalho de professores especialistas na área. Então acredito que tem sido bastante significativo. (Monitor L).
\end{abstract}

Eu não sou desse curso, minha graduação não é licenciatura em música, é licenciatura em história, mas eu vejo que, para que a turma possa prosseguir dentro da metodologia que a professora tá explicando, os monitores precisam equiparar os alunos que não ainda conseguindo aplicar as orientações que a professora deu, dando a esses alunos o suporte técnico, pequenos detalhes técnicos na prática do instrumento que eles ainda não conseguiram aplicar. São orientações que a professora dá, mas para que a gente consiga equilibrar e manter sempre equilibrado e não deixar ninguém pra trás durante o percurso do cronograma dos estudos, a gente tem que ir, todo tempo, recolhendo eles e trazendo de volta para o equilíbrio técnico que todos eles têm que ter para que todos eles consigam chegar onde a gente tá dentro do cronograma. (Monitor J).

Os relatos acima corroboram com o fundamento de troca de saberes contido no ensino coletivo, pois, tanto o aluno do grupo de extensão ganha com a ajuda do monitor, quanto o monitor em poder aprender colaborando com o desenvolvimento deste aluno. É 
interessante também observar a fala do monitor L quando diz: "nossa função tem sido pedagógica, nossa função tem sido formativa", pois, ele exprime a importância da experiência formativa que vivencia enquanto monitor ao reconhecer sua função pedagógica.

Os monitores foram questionados também sobre qual a maior dificuldade que eles percebem que os alunos têm com relação à aprendizagem na metodologia. Sobre esse tópico escolheu-se as três citações abaixo por melhor ilustrarem as principais sinalizações realizadas por eles referente ao assunto.

Eu vejo que a dificuldade seria o estudo autônomo, vamos dizer assim, aquele que [...] aprende com acompanhamento, mas, não pratica [...] Então o ideal seria gerar a consciência, o próprio aluno ter a consciência de que é preciso estudar em casa e praticar para que ele mesmo venha se desenvolver e quando ele chegar na sala ele observar que o desenvolvimento dele é fruto do trabalho e do estudo que ele está fazendo constantemente. (Monitor $\mathrm{H}$ ).

Uma dificuldade que eu vejo com os alunos, pelo menos que eu pude ouvir de pessoas que eu tenho auxiliado, é que de acordo com a nossa metodologia nós trabalhamos todos os detalhes técnicos para que depois nós possamos aplicar em frases musicais [...] Nós temos um tempo, que não é prolongado, realmente é o ideal, eu vejo que é o necessário para construir a postura da pessoa, construir toda a técnica e durante esse tempo eu vejo muita "desestimulação" porque as pessoas não veem o retorno da musiquinha, no trechinho musical que é aquilo que eles esperam que vai acontecer do dia pra noite e não é assim, é uma construção. (MONITOR J).

O que eu posso perceber de dificuldade na sala de aula é que, pelo menos na parte de adultos, primeiro é a assiduidade, porque geralmente os jovens adultos são mais assíduos porque eles tem um certo tempo livre pra participar dessa prática, os adultos geralmente encaixam esse tempo livre entre as suas atividades de trabalho ou de estudo e ai acaba que muitas vezes ele não consegue comparecer ou comparecendo menos tempo do que a aula devidamente é estruturada, ou então comparece a apenas uma hora da aula e isso, a longo tempo, a gente percebe que é um reflexo no desenvolvimento daquele próprio estudante. (Monitor A).

Em parâmetros gerais os monitores sinalizaram que a falta do estudo autônomo, a falta de paciência necessária para o progresso e a pouca assiduidade (este último com relação ao público adulto) são as principais dificuldades que eles percebem que os alunos têm para progredirem em seus estudos na metodologia do ensino coletivo de cordas.

Sobre essas observações pode-se compreender que as dificuldades encontradas com relação aos alunos da metodologia do ensino coletivo de cordas não diferem em elevado grau de qualquer outro tipo de metodologia ou estudo. Para melhor embasar a finalidade do “ensinar" (seja no ensino coletivo ou em qualquer outra metodologia de ensina) faz-se necessário citar Paulo Freire (2013) em que afirma: "Saber ensinar não é transferir 
conhecimento, mas, criar as possibilidades para a sua própria produção ou sua construção" (FREIRE, 2013, p. 47).

Assim, entende-se que decerto é necessária uma maior perseverança e paciência com relação ao período inicial do estudo na metodologia do ensino coletivo de cordas, pois, esse é o momento em que se constrói a "base" de todo o seu desenvolvimento com relação à compreensão da importância da postura, de como segurar o instrumento corretamente e os princípios técnicos para a melhor emissão sonora, mas, a responsabilidade do aluno com sua assiduidade as aulas e a rotina de estudos em casa é primordial para a sua evolução.

Quando questionados sobre em quais aspectos ser monitor de ensino coletivo de cordas na UFC acrescenta na formação deles, alguns monitores que ainda não haviam se pronunciado colaboram com suas visões. Segue abaixo tais citações:

Eu acho superimportante porque já é um preparo docente. Quando a gente se formar é isso que a gente vai fazer, só que, ao invés de a gente ser o monitor, vamos ser os principais responsáveis pela educação musical desses alunos. Então já é um preparo, um estágio, pode-se dizer. (Monitor Av).

É um processo que nunca é só de ensino, você tá sempre aprendendo enquanto está ensinando. De repente a gente tá fazendo uma coisa e tendo uma experiência, isso eu falo pela experiência que a gente tá tendo com as turmas infantis. Você não fazia isso antes e quando você tem a oportunidade de trabalhar com aquilo, você percebe que adora fazer isso e você jamais teria essa oportunidade de se conhecer se você não tivesse a oportunidade de ser monitor. (Monitor $\mathrm{Al}$ ).

O ensino de cordas aqui começou mais ou menos em 2015 e eu fui um dos primeiros alunos, eu participei do comecinho da formação daqui e no decorrer do aprendizado e no decorrer do processo de me tornar monitor das turmas de extensão eu pude ter um outro olhar sobre o processo de aprendizagem porque no começo você se preocupa em estudar e se desenvolver, mas quando você se torna um monitor, você também lembra dessa etapa, mas lembra com outros olhos e lembra quando você era aluno e meio que entende as dificuldades e os estímulos que os alunos precisam para se desenvolver. Então eu posso perceber que isso me ajuda bastante, me ajuda a me tornar um facilitador muito melhor do que se eu tivesse chegado de paraquedas aqui. (Monitor B).

Os monitores são bastante claros quanto à importância do saber de experiência para a própria construção docente, assim, entende-se que o sujeito da experiência deve ser um ponto de chegada, que recebe, que se expõe, esse é o sujeito verdadeiramente aberto a sua própria transformação, então, admite-se a importância da experiência sendo esta o modo como alguém vai respondendo ao que lhe acontece e por esse motivo a experiência é singular, particular, e única a cada indivíduo (BONDÍA, 2002, p. 27).

A fala do monitor Al quando expressa: "quando você tem a oportunidade de 
trabalhar com aquilo, você percebe que adora fazer isso e você jamais teria essa oportunidade de se conhecer se você não tivesse a oportunidade de ser monitor" vai de encontro com Bondía (2002, p. 20) que propõe "pensar a educação a partir do par experiência/sentido" em que a experiência lhe cativou, pois, foi vivenciada verdadeiramente e isso lhe mostrou um caminho, um sentido, uma possibilidade nova para aperfeiçoar e seguir se assim desejar.

Os monitores foram questionados também se eles percebiam alguma diferença no tratamento aluno-monitor com relação ao tratamento aluno-professor e sobre esse ponto foi verificado que muitas vezes pelo fato de os alunos saberem que os monitores também são alunos (em formação para serem professores) ou até mesmo em algumas turmas pela proximidade de faixa etária eles sentem-se mais a vontade de tirar dúvidas com os monitores que com os professores segundo o monitor $\mathrm{R}$ pontuou na citação a seguir:

O aluno tirar dúvida no final da aula acontece bastante, principalmente com os mais iniciantes. Acho que às vezes o aluno vê o professor como uma "entidade", um "semideus" e fica com vergonha de perguntar pro professor, fica constrangido [...] como ele vê que o monitor tá mais ou menos na mesma faixa etária, que também é um estudante ele se sente mais a vontade pra perguntar do que chegar pro professor e fazer a pergunta. (Monitor R).

Há monitores que ficam a frente de algumas turmas específicas (sempre orientados pelos professores) e desempenham um papel que exige competências como a realização de planejamento e uma maior percepção geral do progresso da turma trabalhada. Diante dessa realidade os monitores foram questionados sobre como é feita a divisão dos conteúdos e como eles lidam com esses conteúdos. Sobre essa questão têm-se as citações abaixo.

A gente de 15 em 15 dias cria um plano de aula. Cada aula um desses monitores fica a frente da aula e os outros dois ficam como auxiliares [...]. A gente cria o plano de aula baseado no que a gente acredita que a turma vai conseguir aprender de forma significativa, a gente não sai atropelando ou faz devagar demais, tem que ter esse cuidado pra que as pessoas que aprendem com facilidade não se sintam entediadas na aula, não sintam como se não estivessem aprendendo, e para as pessoas com mais dificuldade não sintam que estão avançando demais pra elas. A gente sempre tem esse cuidado, qual o exercício que eu vou fazer, a maioria das pessoas está com essa dificuldade, então vamos fazer esse exercício antes trabalhar o método. (Monitor A).

A gente percebe quais são as dificuldades, mas, a gente pergunta pra que eles realmente adquiram essa prática de se auto apreciar [...]. A gente não tem como ver todo mundo, a dificuldade de cada um. Então a gente chega na aula e pergunta qual a dificuldade de vocês? Eles falam e a gente tenta explicar, mesmo que a gente já tenha falado como a gente pode consertar isso. No início, quando a gente tava fazendo o planejamento a gente utilizava muito exercícios de arco, de postura, ai adentrou no método. A gente meio que fazia uma previsão de o que a gente achava 
que eles iam conseguir fazer e ver na hora qual exercício que podia ajudar eles naquele momento, porque varia de aula pra aula o desenvolvimento deles [...]. Então a gente tem que fazer essas revisões pra que a gente tente caminhar um pouco mais junto. (Monitor V).

A turma infantil [...] eu realmente preciso esperar que a professora me diga, me oriente e eu e meus colegas fazemos o possível. A questão, por exemplo, dos alunos do infantil que eu percebo que é complicada porque todos vêm, é que nem todos eles, é perceptível, estão lá por vontade própria e isso dificulta um pouco o aprendizado. Então, além disso, tem que equilibrar as crianças que tem muita energia e as crianças que estão tendo dificuldade de desenvolver a musculatura. Essa equiparação é muito complicada de fazer, porque a gente tem que concentrar a energia das crianças que tem muita e equilibrar com as crianças que são um pouco mais pacíficas e tem um andamento mais largo. (Monitor J).

Os relatos dos monitores $\mathrm{A}$ e $\mathrm{V}$ demonstram a disciplina e empenhos que é empregado com relação às atividades de planejamento, assim como a participação dos próprios estudantes na orientação do conteúdo estudado. É interessante observar que sempre os monitores fazem alusão a autopercepção que o estudante deve ter quanto ao seu próprio desenvolvimento, logo, a autopercepção é um dos pilares que formam o ensino coletivo de cordas eficaz.

O monitor $\mathbf{J}$ (monitor de uma das turmas infantis) pontuou que precisa da ajuda e do direcionamento da professora com relação à determinação dos conteúdos e estruturação do planejamento por enfrentar uma realidade diferente, pois, segundo seu relato existem crianças que frequentam as aulas das turmas de extensão de ensino coletivo de cordas infantis que não querem está lá e vão por imposição dos pais.

A música de certo tem um potencial social indiscutível, envolve, encanta, porém, não se pode afirmar que todos são cativados por seu potencial e quanto a essa questão das individualidades orienta Freire (2013): “O respeito à autonomia e à dignidade de cada um é um imperativo ético e não um favor que podemos ou não conceber uns aos outros" (FREIRE, 2013, p. 58). Ciente desta realidade a professora orientadora da atividade de extensão infantil estabeleceu um período de observação/adaptação em que as crianças têm aulas de musicalização com um pressuposto mais lúdico e em seguida aulas com o instrumento. Após esse período são identificadas as crianças que realmente não querem participar das atividades e a fim de respeitar a individualidade das mesmas a professora coordenadora do projeto conscientiza os pais da importância de considerarem tais questões.

No que se refere à heterogeneidade das turmas (fato que foi pontuado na citação do monitor J) Ying (2012, p. 38) esclarece:

O desafio do professor de ensino coletivo é ensinar um só conteúdo com abordagens 
diferentes de acordo com as diversas capacidades de compreensão e desenvolvimento na aquisição de competências. Para tanto é indispensável que o professor também seja capaz de escutar a emoção da criança, suas dificuldades e sentimentos de bem-estar. (YING, 2012, p. 38)

Quando aferidos sobre como é a relação professor-monitor os monitores afirmaram que é uma relação bastante saudável e com muita compreensão, pois, como muito bem resume a fala do monitor A: "Em momento algum a gente foi posicionado a ensinar o que a gente não sabe".

A última pergunta feita aos monitores foi se existe algum ponto que eles acreditam que precisa melhorar no ensino coletivo de cordas da UFC e sobre isso as falas dos monitores V e A refletem os itens mais apontados: a falta de espaço e a falta de equipamentos. Sobre tais necessidades o monitor $\mathrm{V}$ relatou: "Precisamos de mais espaço. $\mathrm{O}$ curso não foi pensado para que tivesse o ensino de instrumentos, foi mais pensado para canto, então, são poucas salas, não tem salas de estudo" em seguida a esta fala o monitor A acrescentou: "Não só a estrutura física, mas, também a gente tem problemas com a estrutura de equipamentos". Faltam estantes, faltos instrumentos.

A redução de verbas para as universidades públicas do país é uma realidade que interfere na manutenção e evolução do desempenho de atividades como as desenvolvidas pelos grupos de extensão de ensino coletivo de cordas da Universidade Federal do Ceará, no entanto, continua-se tal trabalho com o revezamento de salas e equipamentos com os demais grupos de extensão do curso de música e com a conscientização dos estudantes ingressantes de que os mesmo devem ter seu próprio equipamento de estudo como o instrumento, estante de partitura e pasta.

\section{CONCLUSÃO}

Este trabalho apresentou como se deu o processo de inclusão da metodologia de ensino coletivo de cordas no curso de música da Universidade Federal do Ceará e como este se transformou em um dos maiores projetos de extensão do curso, atendendo a crianças, jovens e adultos vinculados à instituição ou não.

O crescimento dos grupos de extensão de ensino coletivo de cordas da universidade fez emergir a importância da participação dos monitores nesse processo e a fim de 
compreender tal participação e a relevância dessa experiência na formação dos mesmos, eles foram entrevistados e como resultado dessa entrevista, podemos pontuar que os monitores desempenham funções não apenas de apoio nas aulas de ensino coletivo, mas, também atuam a frente das turmas com atribuições como a realização de planejamentos e divisão de conteúdo. A presença deles em sala de aula desperta uma identificação positiva com o estudante iniciante que se sente mais à vontade em procura-los para sanar dúvidas.

A experiência em atuar como monitor das turmas de ensino coletivo de cordas da UFC propicia aos discentes um saber de experiência, a descoberta da possibilidade de um caminho a seguir, a prática pedagógica da teoria aprendida em sala de aula que somente foi possível (em uma maior escala) pela criação dos grupos de extensão.

\section{REFERÊNCIAS}

BONDÍA. Jorge Larossa. Notas sobre a experiência e o saber de experiência. Tradução: João Wanderley Geraldi. Revista Brasileira de Música: São Paulo, 2002.

DUARTE, Jorge; BARROS, Antônio (org.). Métodos e técnicas de pesquisa em comunicação. $2^{a}$ ed. São Paulo: Atlas, 2006.

FREIRE, Paulo. Pedagogia da autonomia: saberes necessários à prática educativa. 46 ed. Rio de Janeiro: Paz e Terra, 2013.

GIL, Antônio Carlos. Estudo de caso. São Paulo: Atlas, 2009.

LIMA, Marlucia de Lima; FERREIRA, Gabriel Nunes Lopes. A formação docente e musical através do ensino coletivo de cordas de violino: um relato de experiência no curso de extensão da Universidade Federal do Ceará. In. Encontro Nacional de Ensino Coletivo de Instrumento Musical. Ensino Coletivo de Instrumentos Musicais: Teorias e práticas, 7. Sobral. Anais... Sobral: ENECIM, 2016. p. 263-270. 